\title{
Profile of Social Skills in Students with Autism Spectrum Disorder
}

\section{Georgia Strofylla, Sofia Charitou, Katerina Asonitou, Dimitra Koutsouki}

Laboratory of Adapted Physical Activity, Developmental and Physical Disabilities, School of Physical Education and Sport Science, National \& Kapodistrian University of Athens, Athens, Greece

Email: gstrofylla@phed.uoa.gr

How to cite this paper: Strofylla, G., Charitou, S., Asonitou, K., \& Koutsouki, D. (2021). Profile of Social Skills in Students with Autism Spectrum Disorder. Advances in Physical Education, 11, 195-206. https://doi.org/10.4236/ape.2021.112015

Received: February 16, 2021

Accepted: May 7, 2021

Published: May 10, 2021

Copyright ( 2021 by author(s) and Scientific Research Publishing Inc. This work is licensed under the Creative Commons Attribution International License (CC BY 4.0).

http://creativecommons.org/licenses/by/4.0/

\begin{abstract}
Typical socialization and communication deficits constitute the defining features of children with Autism Spectrum Disorder. The purpose of this study was to identify the social skills profile of a total of 86 Greek students with ASD, aged 7 - 17 years old. Furthermore, it was examined the role of age, gender, language ability and school curriculum in order to determine the possible associations with the deficiency in social functioning. The instrument used was the Autism Social Skills Profile (ASSP) questionnaire and was filled by the special teachers. The findings reported significant social issues in all subscales of ASSP questionnaire for students with ASD. Comparisons of age and gender do not indicate any significant differences in relation to social skills. Language ability and school curriculum seem to mostly affect the development of social skills of students with ASD.
\end{abstract}

\section{Keywords}

Social Skills, Autism Spectrum Disorder, Quality of Life, Autism Social Skills Profile Questionnaire

\section{Introduction}

Autism Spectrum Disorders (ASD) are a lifelong neurodevelopmental disorder with large heterogeneity in its characteristics. There is growing evidence from longitudinal studies that the core symptoms associated with ASD tend to emerge within the first two years of life (Estes et al., 2015). The defining features are poor social interaction, deficits in social communication, language delay or impairment, restricted and stereotyped patterns of behavior, interests and activities (APA, 2013). ASD are mainly characterized as a social and cognitive disorder. The majority of children with ASD have been found to exhibit deficiencies in 
social functioning that affect their everyday social interaction with their peers.

Social skills are an important aspect for a child's growth, including children with ASD. Social functioning can be defined as a set of abilities that help children to behave in acceptable ways to a particular social situation and allow them to interact effectively with other people (Yeo \& Teng, 2015). The triads of social reciprocity deficits are rigidity of self-control behavior and thought, perspective-talking difficulties and difficulties in communication skills (Sanratanna, Maneerat, \& Srevisate, 2014). Deficits in these domains may be markers for later social-developmental problems. Some of the typical social issues that might be present in children with ASD include difficulty in initiating conversation and understanding jokes, idioms or metaphorical expressions, problems with nonverbal communication such as gestures and facial expressions, difficulties in developing language skills in order to communicate their thoughts and express themselves (Christopher \& Shakila, 2015; Bohlander, Orlich, \& Varley, 2012). It is widely accepted that the significant social issues that are present in students with ASD not only can negatively affect their academic performance but also their emotional life. So, it is of major importance to detect the early signs of autism in order to apply effectively interventional programs. Most of the researchers are focusing mainly on the differences between ASD and other developmental disorders, rather than describe the disorder in detail. Furthermore, most of the studies examine the effect of school type (inclusive classrooms, special schools, typical classes with supporting teachers) rather than the school curriculum that used in special classes in order to describe the differences.

Purpose of the current research was twofold. The first one is the social skill's profile classification of students' with ASD from Greece. The second objective of it was mainly evaluated the possible associations of social skills with another variable such as gender, age, language ability and school curriculum of children with ASD living in Greece.

\section{Method}

\subsection{Participants}

We recruited a convenience sample of eighty-six students $(\mathrm{N}=86,66$ males and 22 females), with diagnosed Autism Spectrum Disorders, between the ages of 7 to 17 years old $(\mathrm{M}=13.05$ years old). IQ scores extracted from the personal files of the participants. Students were classified in two age groups: 7 - 12 years old $(\mathrm{N}=29)$ and $13-17$ years old $(\mathrm{N}=57)$. All participants were attended classes in primary and secondary public special education schools from Northern Greece. Finally, according to their language ability, the majority of students were identified as nonverbal $(\mathrm{N}=22), \mathrm{N}=18$ students use only single word or short phrases, $\mathrm{N}=17$ students were above the average, $\mathrm{N}=15$ students were in the average and $\mathrm{N}=14$ students were below the average.

\subsection{Measures}

The Autism Social Skills Profile (ASSP) (Bellini \& Hopf, 2007) questionnaire was 
translated and adapted in Greek language (Papaefstathiou, 2014). The ASSP was developed to identify specific social skill deficits in children and adolescents with ASD, between the ages 6 - 17 years old. Furthermore, the ASSP questionnaire can be used as an intervention planning tool that focuses on specific social skills deficits. Finally, ASSP questionnaire assists the planning and monitoring of intervention programs.

The ASSP questionnaire can be completed by a parent, a caregiver or any other professional who is working in special education. It requires approximately 10 to 15 minutes to be completed and the items are rated on 4-point Likert scale ranging from never to very often (never $=0$, sometimes $=1$, often $=2$, very often $=3$ ), high scores corresponding to positive social behaviors. According to Bellini and Hopf study (2007), the ASSP questionnaire has excellent psychometric properties (internal consistency, test-retest reliability, concurrent validity) and is consisted of 49 items that they are classified in three different subscales which are labeled as Social Reciprocity (26 items), Social Participation/Avoidance (14 items), and Detrimental Social Behaviors (9 items).

\subsection{Procedure}

Participants were recruited from classrooms in nine special school settings in urban and suburban areas of Greece. The Autism Social Skills Profile (ASSP) questionnaire was filled by the special teachers of students with ASD. To carry out the data collection, the research team set up an informative meeting with special educators in order to explain in detail the purpose of the study. At the same time consent forms were given to the principal of the school, to teachers and parents/caregivers. The ASSP questionnaire was sent by email to the participants with all additional instructions about the completion of students' profile that was included on the cover sheet. Additionally a short demographics questionnaire was created to gather further information, including the child's age, gender, language ability and school curriculum. Teachers were asked to return the completed questionnaire to the research team in the self-addressed, stamped envelope provided, along with the brief questionnaire.

\subsection{Statistical Analysis}

Descriptive statistics (mean, standard deviation, frequencies) and reliability Cronbach's alpha test for the three subscales of the ASSP were calculated. One way Analysis of Variance and Independent T-test was carried out in order to determine whether there are any statistically significant differences among group means. In order to further investigate the relationship between independents variables (gender, age, language ability and school curriculum) and the three subscales of the questionnaire, bivariate correlation analyses were assessed using Pearson's coefficients. Statistical analysis of the data was performed using Statistical Package for Social Sciences (SPSS) (version 25.0) and statistical significance was set at $p<0.05$ (Norusis, 2012). 


\section{Results}

Cronbach's alpha was used to ensure the reliability of the ASSP Questionnaire, internal consistency for each of the three subscales. The alpha coefficient for the twenty-six items of Social Participation/Avoidance subscale is $\alpha=0.891$, for the fourteen items of Social Reciprocity subscale is $\alpha=0.962$ and for the nine items of Detrimental Social Behaviors subscale is $\alpha=0.779$, respectively, suggesting that the items have relatively high internal consistency. So, the ASSP Questionnaire is a reliable tool for assessing social skills of students with ASD.

\subsection{Social Skills in Students with ASD in ASSP Questionnaire}

Descriptive statistics (mean and standard deviation) were applied in order to provide more information about the observations that have been made in the ASSP questionnaire and are shown in Table 1 . The possible answers for the questions ranging from never (0) to very often (3). Specifically, Social Reciprocity subscale includes 26 items that were dealing with successfully social interaction and language skills. The response "sometimes" take turns during games and activities, verbally expresses how he/she was feeling, join a conversation without interrupting, respond to questions directed at him/her, introduce self to others etc. is answered at $50 \%$ of participants $(\mathrm{M}=1.05, \mathrm{SD}=0.734)$ (Table 2). The Social Participation/Avoidance subscale contains 14 items that evaluate the engagement or withdrawal from social participation. In frequency of $54.7 \%$ of students with ASD sometimes joins in activities with peers, invites peers to join in activities, interacts with groups of peers, responds to peer invitations to join in activities, exhibits fear or anxiety about social interactions, engages in solitary activities near peers etc. $(\mathrm{M}=1.36, \mathrm{SD}=0.631)$ (Table 3$)$. Finally, the subscale Detrimental Social Behaviors includes 9 items related to behaviors that are inappropriate and are connected with deficits in social interactions with peers. In frequency of $57 \%$ of students with ASD sometimes misinterpret the intentions of others, make inappropriate comments, ends conversations abruptly, experiences negative peer interactions, engages in socially inappropriate behaviors etc. $(M=$ $1.14, \mathrm{SD}=0.671)($ Table 4$)$.

Statistical criteria of One-Way Analysis of Variance (ANOVA) and Independent T-test were carried out in order to investigate whether there were any statistically significant differences between the group means of the tested variables. According to the gender differences, there was no significant difference in Social

Table 1. Mean and standard deviation of three subscales.

\begin{tabular}{cccc}
\hline & Social Reciprocity & $\begin{array}{c}\text { Social Participation/ } \\
\text { Avoidance }\end{array}$ & $\begin{array}{c}\text { Detrimental } \\
\text { Social Behaviors }\end{array}$ \\
\hline $\mathrm{N}$ & 86 & 86 & 86 \\
Mean & 1.05 & 1.36 & 1.14 \\
St. Deviation & 0.734 & 0.631 & 0.671 \\
\hline
\end{tabular}


Table 2. Frequency of social reciprocity subscale.

\begin{tabular}{ccc}
\hline & $\mathrm{F}$ & $\%$ \\
\hline Never & 20 & $23.3 \%$ \\
Sometimes & 43 & $50 \%$ \\
Often & 22 & $25.6 \%$ \\
Very Often & 1 & $1.2 \%$ \\
Total & $\mathrm{N}=86$ & $100 \%$ \\
\hline
\end{tabular}

Table 3. Frequency of social participation/avoidance subscale.

\begin{tabular}{ccc}
\hline & $\mathrm{F}$ & $\%$ \\
\hline Never & 5 & $5.8 \%$ \\
Sometimes & 47 & $54.7 \%$ \\
Often & 32 & $37.2 \%$ \\
Very Often & 2 & $2.3 \%$ \\
Total & $\mathrm{N}=86$ & $100 \%$ \\
\hline
\end{tabular}

Table 4. Frequency of detrimental social behaviors subscale.

\begin{tabular}{ccc}
\hline & $\mathrm{F}$ & $\%$ \\
\hline Never & 13 & $15.1 \%$ \\
Sometimes & 49 & $57 \%$ \\
Often & 23 & $26.7 \%$ \\
Very Often & 1 & $1.2 \%$ \\
Total & $\mathrm{N}=86$ & $100 \%$ \\
\hline
\end{tabular}

Reciprocity subscale between male and female with ASD $(\mathrm{t}(84)=-0.718, p=$ 0.457), in Social Participation/Avoidance $(\mathrm{t}(84)=-0.717, p=0.751)$ and Detrimental Social Behaviors $(\mathrm{t}(84)=-0.079, p=0.937)$, respectively. Specifically, the above subscales of ASSP questionnaire are not influenced by the gender and both males and females with ASD not only participate in social activities with peers, but also engage in socially inappropriate behaviors with the same way. According to the age differences, the results from Independent $\mathrm{T}$-test showed no significant difference in all subscales between the two age groups $(7-12$ years old \& $13-17$ years old) of students with ASD (Social Reciprocity: $\mathrm{t}(84)=-1.041$, $p=0.301$, Social Participation/Avoidance: $\mathrm{t}(84)=-0.163, p=0.871$, Detrimental Social Behaviors: $\mathrm{t}(84)=-1.524, p=0.132$, respectively). More specifically, the three subscales of ASSP questionnaire are not influenced by the age and both youngest and oldest students with ASD participate in social activities, and interact with peers in the same way. Results about school curriculum are very interesting. There was a statistically significant difference between schools as demonstrated by one-way ANOVA in Social Participation subscale $(\mathrm{F}(8,77)=3.038, p$ $=0.005)$. Specifically, students with ASD who are attending in Special Vocation- 
al Secondary and High School of Peristeri $(\mathrm{M}=1.88, \mathrm{SD}=0.500)$ participate more often in social skills than the students with ASD that are studying in Special Elementary School of Corinth $(\mathrm{M}=1.11, \mathrm{SD} .=0.471)$. Similarly, in Social Reciprocity subscale it was found significant statistical differences $(\mathrm{F}(8,77)=$ 4.104, $p=0.000$ ) between schools. Students with ASD who are studying in Special Vocational Secondary and High Scholl of Peristeri $(\mathrm{M}=1.81, \mathrm{SD}=0.544)$ join in activities with peers frequently than the students with ASD who are studying in Special Secondary School of Elefsina $(M=1.13, S D=0.354)$. Finally, there was a statistically significant difference between Special Vocational and Training Center of Patras and Special Elementary School of Corinth in Detrimental Social Behaviors subscale $(\mathrm{F}(8,77)=3.395, p=0.002)$. Specifically, students with ASD who are attending in Special Vocational and Training Center of Patras $(\mathrm{M}=1.71, \mathrm{SD}=0.488)$ engages in socially inappropriate behaviors more often than the youngest students with ASD who are studying in Special Elementary School of Corinth $(M=1.06, S D=0.539)$. Statistical significant differences were found in all three subscales of ASSP questionnaire and students' with ASD language abilities. It was found statistical significant differences in the Social Reciprocity subscale $(\mathrm{F}(8,77)=27.884, p<0.05)$, in Social Participation/Avoidance subscale $(\mathrm{F}(8,77)=14.920, p<0.05)$ and in Detrimental Social Behaviors $(\mathrm{F}(8,77)=7.390 . p<0.05)$. According to the Post-Hoc tests, students with ASD and language abilities above the average are dealing more succesfully social interaction $(\mathrm{M}=1.82, \mathrm{SD}=0.529)(p<0.05)$, social participation $(\mathrm{M}=$ $1.94, \mathrm{SD}=0.556)(p<0.000)$ and they are experiencing negative peer interactions $(\mathrm{M}=1.35, \mathrm{SD}=0.493)(p<0.05)$ than the other group of students with ASD that have poor language abilities.

\subsection{Correlation Analyses between Subscales of ASSP Questionnaire Using Pearson's Coefficients}

According to the results, it was found strong relation between Social Participation/Avoidance and Social Reciprocity subscale $(r=0.7, p>0.05)$ and medium relation with Detrimental Social Behaviors $(\mathrm{r}=0.380, p>0.05)$. Last but not least, the Social Reciprocity subscale and Detrimental Social Behaviors subscale it seems to have low association ( $r=0.297, p=0.006)$.

\section{Discussion}

Children with Autism Spectrum Disorder as described previously experience severely deficits in social and communication skills and interaction, generally. Those deficits have a negative impact on different aspects of development of children with ASD and affect their overall quality of life. Since difficulties in social domain constitute one of the defining core symptoms of children with ASD, it is of major importance for special therapists and parents to pay attention and to work exclusively on this domain in order to improve the social reciprocity deficits (Dekker et al., 2018). An appropriate educational programme adapted in special needs of children with ASD will benefit them on the three areas of so- 
cial skills deficits namely behavioral, affective and cognitive (Yeo \& Teng, 2015). The first goal of the current study was to identify the most frequently occurring social skills deficits among students with ASD. According to the results, Greek children and adolescents with ASD, aged 7 - 17 years old, exhibit a variety of socialization deficits. These results agree with previous studies as children with ASD appear typical social and communication issues (White, Koenig, \& Scahill, 2010; Chung, Reavis, Mosconi, Drewry, Matthews, \& Tassé, 2007; White, Koenig, \& Scahill, 2007; Anderson, Moore, Godfrey, \& Fletcher-Flinn, 2004; Hill \& Frith, 2003). The social skill's profile of students' with ASD was evaluated with Autism Social Skills Profile (ASSP) questionnaire, which developed to identify specific social skill deficits in children and adolescents with ASD. Participants showed deficits in social interaction and perspective-talking difficulties as well as deficits in engagement or withdrawal from social participation. According to Badiah (2018), lack of social skills can lead to unsuccessful social relationships with peers, a decline in employment and in independent life as well as severe mental health problems. It is worth mentioned that students with ASD did not exhibit items related with behaviors that are inappropriate and are connected with deficits in social interactions with peers. Consequently, students with ASD do not successfully engaged in social interaction with peers but also do not exhibit inappropriate behaviors and that is a positive aspect.

The second aim of this study was to evaluated the possible relation of social skills with another variables such as gender, age, language ability and school settings. According to past studies, gender is a possible variable that can affect the social and communication skills as there are at least four boys diagnosed with ASD for every girl (Elsabbagh et al., 2012) and two males for each female have seriously intellectual deficits (Dworzynski, Ronald, Bolton, \& Happé, 2012). In the present results do not seem to exist any significant differences in the gender variable in relation to the total score of ASSP questionnaire. According to Constantino \& Charman (2012) study, males and females with ASD do not indicate significant differences in intellectual abilities, behavior and emotion, accordingly. However, it is generally accepted that gender has a great impact on many aspects of a child's growth, for example, boys tend to have better motor skills whereas girls seem to have better interpersonal and emotional abilities (Rivet \& Matson, 2011). Van Wijngaarden-Cremers, van Eeten, Groen, Van Deurzen, Oosterling and Van der Gaag (2014) conducted a meta-analysis of 22 studies in order to investigate gender differences in children with ASD. They found that, males and females with ASD demonstrate similar symptom severity in terms of communication and social behavior. On the contrary, Head, MacGillivray, \& Stokes (2014), found that females with ASD have more developed social skills than males with ASD, using the friendship questionnaire (FQ). Similar results were reported by Hiller, Young, \& Weber (2014). It was found that girls with ASD were capable of joining in activities with peers but had difficulty of maintaining them, whereas boys with ASD had difficulty with both initiating and maintaining. Also, girls engage in socially inappropriate behaviors less often 
than boys and recognize the "body language" of others better than boys. It is interesting to mention that on Mahendiran et al. (2019) study females with ASD performing lower scores than males with ASD in the communication, leisure, and social skill areas.

Age is a variable that has been studied from researchers in order to examine the possible associations with social engagement in children with ASD. According to the age differences, the results showed no significant difference in all three subscales of ASSP questionnaire between the two age groups (7 - 12 years old \& 13 - 17 years old) of students with ASD. More specifically, social skills are not influenced by the age and both youngest and oldest students with ASD participate in social activities, and interact with peers in the same way. Similar results were mentioned by Pan (2009) study. The purpose of that study was to examine the associations of age, social engagement and physical activity in children with ASD. It was found that children with ASD have the same socialization abilities as they grow. Children with ASD characterized by speech delays and a restricted range of social communication skills (Sansosti \& Powell-Smith, 2008). Due to deficits on verbal and nonverbal communication skills, children with ASD have a difficulty in initiating and maintaining conversations and requesting subjects. Furthermore, they don't respond to invitations to join in activities or follow the classroom rules and they don't interact with peers during activities (Karkhaneh, Clark, Ospina, Seida, Smith, \& Hartling, 2010). Language abilities for children with ASD become a significant indicator for social skill difficulties (Adams, Gouvousis, VanLue, \& Waldron, 2004). In the present study, were found statistical significant differences in all three subscales of ASSP questionnaire for the variable language abilities. According to the Post-Hoc tests, students with ASD and language abilities above the average are dealing more successfully social interaction, social participation and they are experiencing negative peer interactions than the other group of students with ASD that show poor language abilities. Similar results were mentioned to Matson, Hess \& Mahan study (Matson, Hess, \& Mahan, 2013). They examined verbal communication and challenging behaviors and how they interact with social skills in students with ASD. Researchers found that children and adolescents with ASD that have better communication verbal skills and fewer challenging behaviors they characterized by improved social abilities.

School curriculum in special classes is another variable tested in order to investigate the relation with the development of social abilities in students with ASD. In our study participate in students with ASD who were attended classes entirely in primary and secondary special education schools from different cities of Greece. Schools do play an important role on improving social and communication deficits in children with ASD. Children need a structured adapted educational program in order to enhance their idiosyncratic behavior. School should provide a variety of educational curriculum for students with ASD in order to have opportunities for social interaction (Smith, Groen, \& Wynn, 2000). In the current study, students with ASD who are attending in Special Vocational Sec- 
ondary and High School of Peristeri participate in more often in social skills than the students with ASD that are studying in Special Elementary School of Corinth. Students with ASD who are studying in Special Vocational Secondary and High School of Peristeri join in activities with peers frequently than the students with ASD who are studying in Special Secondary School of Elefsina. It is obvious that the curriculum and educational programs that are applied in special schools are of major importance in improving social skills in students with ASD. Students from Special Vocational Secondary and High School of Peristeri seem to have better social skills than their classmates from Special Elementary School of Corinth and Special Secondary School of Elefsina, respectively. An important point is the fact that in Special Vocational Secondary and High Schools attend students with high-functioning ASD and they are preparing for their acceptance in the higher education (universities).

On the other hand, students with ASD who are attending in Special Vocational and Training Center of Patras engage in socially inappropriate behaviors more often than the students with ASD who are studying in Special Elementary School of Corinth. It is worth mentioning that in Special Vocational and Training Centers attend students with severe ASD symptoms. Consequently, it is obvious that students who attend in Special Vocational Secondary and High Schools do have better social skills than students who attend in Special Vocational and Training Centers. For students with ASD, it is important to provide them an "autism-friendly environment” as described form Jordan (p. 104) (Jordan, 2005). A recent study conducted in Greek students with ASD examined the differences among the different school types such as typical class with supporting teacher, special school and inclusion class. Researchers did not find significant differences in students with ASD who attended in typical classes with supporter teacher, in special schools and in inclusive classes (Syriopoulou-Delli, Agaliotis, \& Papaefstathiou, 2016). According to Jordan (2005), schools should provide students with ASD with the necessary skills they need to have better quality of life in their everyday activities and academic performance. Sulaimani and Gut (2019) propose that should be applied a "hidden curriculum" in students with ASD because seems to be far easier than the traditional curriculum. Alsubaie (2015) described the "hidden curriculum" as the unwritten, unofficial, unintended, and undocumented life lessons that students should be taught in their classrooms.

\section{Conclusion}

In conclusion, children and adolescents with ASD exhibit serious social and communication deficits. Furthermore, from the present results, social skills of students with ASD seem not to be affected from age and gender. Furthermore, language ability and school curriculum are two variables that have a strong association with social issues. The results might be helpful to implement intervention programs with the appropriate adaptations included. Parents and teach- 
ers should pay attention to the heterogeneous characteristics of children with ASD in order to enhance their social development. Parents and teachers need to demand from the government to equip special schools with the appropriate facilities, suitably qualified teachers with adequate training and funds in order to create educational programs that support the development of socialization and interaction with community of students with ASD (Badiah, 2018).

\section{Acknowledgements}

We would like to thank all the special teachers of students with Autism Spectrum Disorder that contributed to conducting this study.

\section{Conflicts of Interest}

The authors declare no conflicts of interest regarding the publication of this paper.

\section{References}

Adams, L., Gouvousis, A., VanLue, M., \& Waldron, C. (2004). Social Story Intervention: Improing Communication Skills in a Child with an Autism Spectrum Disorder. Focus on Autism and Other Developmental Disabilities, 19, 87-94. https://doi.org/10.1177/10883576040190020301

Alsubaie, M. A. (2015). Hidden Curriculum as One of the Current Issue of Curriculum. Journal of Education and Practice, 6, 125-128.

American Psychiatric Association (APA) (2013). Diagnostic and Statistical Manual of Mental Disorders (5th ed.). Arlington, TX: American Psychiatric Association. https://doi.org/10.1176/appi.books.9780890425596

Anderson, A., Moore, D. W., Godfrey, R., \& Fletcher-Flinn, C. M. (2004). Social Skills Assessment of Children with Autism in Free-Play Situations. Autism, 8, 369-385. https://doi.org/10.1177/1362361304045216

Badiah, L. I. (2018). The Importance of Social Skills for Autism. Proceedings of the 2nd INDOEDUC4ALL -Indonesian Education for All, Banjarmasin, 18 October 2018, 20-24. https://doi.org/10.2991/indoeduc-18.2018.7

Bellini, S., \& Hopf, A. (2007). The Development of the Autism Social Skills Profile: A Prelim nary Analysis of Psychometric Properties. Focus on Autism and Other Developmental Disabilities, 22, 80-87. https://doi.org/10.1177/10883576070220020801

Bohlander, A. J., Orlich, F., \& Varley, C. K. (2012). Social Skills Training for Children with Autism. Pediatric Clinics of North America, 59, 165-174. https://doi.org/10.1016/j.pcl.2011.10.001

Christopher, S., \& Shakila, C. (2015). Social Skills in Children with Autism. Indian Journal of Applied Research, 5, 139-141. https://doi.org/10.13140/RG.2.2.20772.78724

Chung, K. M., Reavis, S., Mosconi, M., Drewry, J., Matthews, T., \& Tassé, M. J. (2007). Peer-Mediated Social Skills Training Program for Young Children with High-Functioning Autism. Research in Developmental Disabilities, 28, 423-436.

https://doi.org/10.1016/j.ridd.2006.05.002

Constantino, J. N., \& Charman, T. (2012). Gender Bias, Female Resilience, and the Sex Ratio in Atism. Psychiatry, 51, 756-758. https://doi.org/10.1016/j.jaac.2012.05.017

Dekker, V., Nauta, M. H., Timmerman, M. E., Mulder, E., van der Veen-Mulders, L., van 
den Hoofdakker, B., van Warners, S., Vet, L., Hoekstra, P., \& de Bildt, A. (2018). Social Skills Group Training in Children with Autism Spectrum Disorder: A Randomized Controlled Trial. European Child \& Adolescent Psychiatry, 28, 415-424. https://doi.org/10.1007/s00787-018-1205-1

Dworzynski, K., Ronald, A., Bolton, P., \& Happé, F. (2012). How Different Are Girls and Boys Above and Below the Diagnostic Threshold for Autism Spectrum Disorders? Child and Adolescent Psychiatry, 51, 788-797.

https://doi.org/10.1016/j.jaac.2012.05.018

Elsabbagh, M., Divan, G., Koh, Y. J., Kim, Y. S., Kauchali, S., Marcín, C., Montiel-Nava, C., Patel, V., Paula, C. S., Wang, C., Yasamy, M. T., \& Fombonne, E. (2012). Global Prevalence of Autism and Other Pervasive Developmental Disorders. Autism Research, 5, 160-179. https://doi.org/10.1002/aur.239

Estes, A., Zwaigenbaum, L., Gu, H., St. John, T., Paterson, S., Elison, J. T., Hazlett, H., Botteron, K., Dager, S. R., Schultz, R. T., Kostopoulos, P., Evans, A., Dawson, G., Eliason, J., Alvarez, S., Piven, J., \& IBIS Network (2015). Behavioral, Cognitive, and Adaptive Development in Infants with Autism Spectrum Disorder in the First 2 Years of Life. Journal of Neurodevelopmental Disorders, 7, Article No. 24. https://doi.org/10.1186/s11689-015-9117-6

Head, A. M., MacGillivray, J. A., \& Stokes, M. A. (2014). Gender Differences in Emotionality and Sociability in Children with Autism Spectrum Disorders. Molecular Autism, 5, Article No. 19. https://doi.org/10.1186/2040-2392-5-19

Hill, E. L., \& Frith, U. (2003). Understanding Autism: Insights from Mind and Brain. Philosophical Transactions of the Royal Society of London. Series B, Biological Sciences, 358, 281-289. http://doi.org/10.1098/rstb.2002.1209

Hiller, R. M., Young, R. L., \& Weber, N. (2014). Sex Differences in Autism Spectrum Disorder Based on DSM-5 Criteria: Evidence from Clinician and Teacher Reporting. Journal of Abnormal Child Psychology, 42, 1381-1393.

https://doi.org/10.1007/s10802-014-9881-x

Jordan, R. (2005). Managing Autism and Asperger's Syndrome in Current Educational Provision. Pediatric Rehabilitation, 8, 104-112. https://doi.org/10.1080/13638490500054891

Karkhaneh, M., Clark, B., Ospina, M. F., Seida, J. C., Smith, V., \& Hartling, L. (2010). Social Stories ${ }^{\mathrm{TM}}$ to Improve Social Skills in Children with Autism Spectrum Disorder: A Systematic Review. Autism, 14, 641-662. https://doi.org/10.1177/1362361310373057

Mahendiran, T., Dupuis, A., Crosbie, J., Georgiades, S., Kelley, E., Liu, X., Nicolson, R., Schachar, R., \& Anagnostou, E. (2019). Sex Differences in Social Adaptive Function in Autism Spectrum Disorder and Attention-Deficit Hyperactivity Disorder. Frontiers in Psychiatry, 10, Article No. 607. https://doi.org/10.3389/fpsyt.2019.00607

Matson, J. L., Hess, J. A., \& Mahan, S. (2013). Moderating Effects of Challenging Behaviors and Communication Deficits on Social Skills in Children Diagnosed with an Autism Spectrum Disorder. Research in Autism Spectrum Disorders, 7, 23-28.

https://doi.org/10.1016/j.rasd.2012.07.002

Norusis, M. (2012). IBM SPSS Statistics 21 Guide to Data Analysis. Chicago, IL: SPSS Inc.

Pan, C. Y. (2009). Age, Social Engagement, and Physical Activity in Children with Autism Spectrum Disorders. Research in Autism Spectrum Disorders, 3, 22-31. https://doi.org/10.1016/j.rasd.2008.03.002

Papaefstathiou, E. (2014). Evaluation of Social Skills in Children with Autism Spectrum Disorder. MSc Thesis, Thessaloniki: University of Macedonia.

Rivet, T. T., \& Matson, J. L. (2011). Review of Gender Differences in Core Symptomatol- 
ogy in Autism Spectrum Disorders. Research in Autism Spectrum Disorders, 5, 957-976. https://doi.org/10.1016/j.rasd.2010.12.003

Sanratanna, U., Maneerat, T., \& Srevisate, K. (2014). Social Skills Deficits of Students with Autism in Inclusive Schools. Procedia-Social and Behavioral Sciences, 116, 509-512. https://doi.org/10.1016/j.sbspro.2014.01.249

Sansosti, F. J., \& Powell-Smith, K. A. (2008). Using Computer-Presented Social Stories and Video Models to Increase the Social Communication Skills of Children with High-Functioning Autism Spectrum Disorders. Journal of Positive Behavior Interventions, 10, 162-178. https://doi.org/10.1177/1098300708316259

Smith, T., Groen, A. D., \& Wynn, J. W. (2000). Randomized Trial of Intensive Early Intervention for Children with Pervasive Developmental Disorder. American Journal on Mental Retardation, 105, 269-285.

https://doi.org/10.1352/0895-8017(2000)105\%3C0269:RTOIEI\%3E2.0.CO;2

Sulaimani, M. F., \& Gut, D. M. (2019). Hidden Curriculum in a Special Education Context: The Case of Individuals with Autism. Journal of Educational Research and Practice, 9, 30-39. https://doi.org/10.5590/JERAP.2019.09.1.03

Syriopoulou-Delli, C. K., Agaliotis, I., \& Papaefstathiou, E. (2016). Social Skills Characteristics of Students with Autism Spectrum Disorder. International Journal of Developmental Disabilities, 64, 35-44. https://doi.org/10.1080/20473869.2016.1219101

Van Wijngaarden-Cremers, P. J. M., van Eeten, E., Groen, W.B., Van Deurzen, P. A., Oosterling, I. J., \& Van der Gaag, R. J. (2014). Gender and Age Differences in the Core Triad of Impairments in Autism Spectrum Disorders: A Systematic Review and Meta-Analysis. Journal of Autism and Developmental Disorders, 44, 627-635.

https://doi.org/10.1007/s10803-013-1913-9

White, S. W., Koenig, K., \& Scahill, L. (2007). Social Skills Development in Children with Autism Spectrum Disorders: A Review of the Intervention Research. Journal of Autism and Developmental Disorders, 37, 1858-1868.

https://doi.org/10.1007/s10803-006-0320-x

White, S. W., Koenig, K., \& Scahill, L. (2010). Group Social Skills Instruction for Adolescents with High-Functioning Autism Spectrum Disorders. Focus on Autism and Other Developmental Disabilities, 25, 209-219. https://doi.org/10.1177/1088357610380595

Yeo, K.J., \& Teng, K.Y. (2015). Social Skills Deficits in Autism: A Study among Students with Autism Spectrum Disorder in Inclusive Classrooms. Universal Journal of Educational Research, 3, 1001-1007. https://doi.org/10.13189/ujer.2015.031208 